\title{
A COMPARATIVE ANALYSIS OF BODY PSYCHOTHERAPY AND DANCE MOVEMENT PSYCHOTHERAPY FROM A EUROPEAN PERSPECTIVE
}

\section{Abstract}

The role of embodiment within contemporary psychotherapy practice and its discussion are gathering momentum, and are part of a paradigm shift in psychotherapy in which theory and practice are being reformulated. Body Psychotherapy (BP) and Dance Movement Psychotherapy (DMP) are playing a leading role in these deliberations. Although these two professions have separate professional bodies, distinct theoretical grounding and clinical methodology, they both place enormous value on the central role of the body and its movement as indicators of relational problems, and as agents of therapeutic change. There are few authors comparing and contrasting Body Psychotherapy and Dance Movement Psychotherapy although they have much in common as they are both embodied, enactive psychotherapies. However, neither their overlaps in theory, methodology and some of their clinical practice nor their distinct character have been sufficiently delineated. This article elucidates some similarities and differences in fundamental assumptions, compares and contrasts definitions and terms, and considers common and contrasting theoretical perspectives, techniques and methods. It is expected that this will contribute to the on-going discussion of the articulation of core characteristics in both professions and will facilitate a better understanding and collaboration between them.

Key words: Body psychotherapy, dance movement psychotherapy, comparative analysis, embodiment 


\section{Introduction}

This article highlights some distinguishing factors and parallels in Dance Movement Psychotherapy (DMP) and Body Psychotherapy (BP). It is inspired by papers such as Payne (2006a) who drew attention to literal marriages between dance movement psychotherapists and body psychotherapists, as a conscious, or at times unconscious, desire to bring the two disciplines together. It follows the discussion that began with Young and Pallaro (2008) who queried whether DMP is a form of psychotherapy or body psychotherapy. It also accords with Karkou and Sanderson (2006) and Zubala and Karkou (2014) who explored the similarities and differences between DMP and its affiliated disciplines of music therapy, art psychotherapy and dramatherapy. We argue that articulating professional boundaries as well as overlaps between DMP and BP may enable more integration within, and between, them without losing any of the uniqueness of each profession. This process is part of a wider move away from a silo effect in the field, or what Clarkson (1999) referred to as schoolism within the psychotherapies, where a training school claims uniqueness without reference to others working in comparable ways. The article is also timely as discussion on embodiment, a common theme in DMP and BP and part of the paradigm shift (Kuhn, 1970) currently taking place across different forms of psychotherapy (Schore, 2012).

More specifically this article considers the broad aims of each psychotherapy, the terminology used, the context of clinical work, client populations, theoretical assumptions, and methodologies. A comparison of historic roots in Europe and research in the fields has been retained for future publications. It is worth noting that our reflections tend to emphasise UK preoccupations. However, since we work internationally, we believe that our analysis will also have relevance globally. 


\section{Definitions and Terms}

Turning to definitions of BP and DMP statements from the European Association Dance Movement Therapy (EADMT) and the European Association for Body Psychotherapy $(\mathrm{EABP})$ are a starting point:

Dance Movement Therapy can be described as the therapeutic use of movement aiming to further the emotional cognitive, physical, spiritual and social integration of the individual (EADMT, 2015, p.1)

Directly or indirectly the body-psychotherapist works with the person as an essential embodiment of mental, emotional, social and spiritual life. He/she encourages both internal self-regulative processes and the accurate perception of external reality (EABP, 1991, p.1)

These broad definitions for BP and DMP clearly demonstrate overlaps. Dance movement psychotherapists would probably recognise their own practice when reading the BP definition; likewise body psychotherapists would agree with the DMP definition to a great extent, but argue that they use different methodologies to achieve integration and wholeness, methodologies that do not draw so heavily on dynamic and interactive movement or other creative expressions.

Whilst we have chosen to employ the umbrella terms of DMP and BP, historically they have not been used universally. This lack of agreed terminology makes for confusion in the dialogue. Indeed, it may not be possible to write definitively about BP or DMP until there are internationally agreed terminologies and competencies for each psychotherapy. The authors' current understanding of the way the two fields are named is as follows.

DMP is the term widely used primarily in the UK since the field was renamed from dance movement therapy to dance movement psychotherapy in 2009 (ADMP, 2009). Dance movement therapy and dance therapy are terms commonly found in Europe (the former is the term formally adopted from the EADMT, while dance/movement therapy or dancemovement therapy are the two terms used in the USA and Australia respectively). Some practitioners also drop the word dance all together and talk about movement psychotherapy. 
In 1991, the EABP adopted the term body psychotherapy to replace terms such as bodyoriented psychotherapy, body-centred psychotherapy, body-mind psychotherapy, and somatic psychotherapy. The USA Body Psychotherapy Association followed this nomenclature. Nevertheless the different terms abide, probably because they carry nuanced meaning for particular writers. Röhricht (2009), for example, writes about body oriented psychotherapy, grouping BP and DMP together, and has used it interchangeably with a new term body oriented psychological therapy. More recently, Cornell (2015) moves freely between body-centred psychotherapies, body oriented psychotherapist, neo-Reichian body therapists, somatic psychotherapy and body psychotherapy. Within the USA the term somatic psychology is used; some regard it as synonymous with BP, others as close, but not quite the same.

Furthermore, the pioneers of BP have developed their own forms of body psychotherapy and nomenclature adding to the confusion. These include, bioenergetics (Lowen, 1975), core energetics (Pierrakos, 1987), biodynamic psychology (Boyesen, 1980), formative psychology (Keleman, 1985), Hakomi (Kurtz, 1990), biosynthesis (Boadella, 1987), bodynamic (Marcher \& Fich, 2010), and Pesso-Boyden therapy (Pesso, 1969). The next generation remain keen to have distinctive brand names such as the Chiron approach (Hartley, 2009) and sensorimotor psychotherapy (Ogden, Minton \& Pain, 2006). In tandem with this, there are some authors bringing together different forms of body psychotherapy (Heller, 2012; Westland, 2015a). Interestingly generic thinking, inclusiveness and integration seems to invite the opposite that is identifying specialism and unique identity to seek particularity, and vice versa.

Both DMP and BP interface with therapies which may contribute to wellbeing, but are forms of psychotherapy falling outside the professional boundaries of the two professions. Other examples are functional relaxation (Schmidt, 200), Body-Mind Centering ${ }^{\circledR}$ (BainbridgeCohen, 2012), psychomotor therapy (Simon, 1929) are all therapeutic practices involving movement work. Some DMP practitioners may also be trained in them, but they are external to the DMP field (Karkou \& Sanderson, 2006). Likewise, body therapies, such as Alexander 
Technique, or cranio-sacral therapy are not aspects of body psychotherapy as these do not address psychological factors such as the unconscious, the therapeutic relationship, and transferential dynamics (Boening, Southwell \& Westland, 2012; Eiden, 2002, Marlock and Weiss, 2015). Finally, "adding a theory of body psychology onto an existing training such as Cognitive Behavioural Therapy or Psychoanalysis does not make the practitioner a body psychotherapist" (Boening, Southwell \& Westland, 2012, p. 4).

\section{Some Fundamental Assumptions}

DMP and BP regard body and mind as inseparable and forming a functional unity (Laban \& Lawrence, 1974; Levy, 1988; Reich, 1942, 1949; Stanton-Jones, 1992); the term bodymind, first coined by Dychtwald (1986), a Gestalt therapist, has emerged to reflect this (Totton, 2003). Both disciplines agree that beliefs, thoughts and feelings are reflected in the body and affect gesture, posture, and breathing patterns, and that movement reflects aspects of our personality and history of relating (Keleman, 1985; Levy, 1988; Lowen, 1975; North, 1972; Ogden et al, 2006; Reich, 1942; Stanton-Jones, 1992).

BP and DMP honour subjective experiences such as physical sensations, embodied presence and relationship, as well as interventions which integrate and re-vitalise (Berrol, 1992, 2006; Krantz, 2012; Nolan, 2012; Ogden et al., 2006; Payne, 2015; Rolef Ben-Shahar, 2014; Westland, 2015a). Both professions accept that any physical changes in posture or autonomic nervous system activity will affect mood, perception, sensory experience, cognition and well-being (Carroll, 2009; Levy, 1988; Sletvold, 2014; Westland, 2015a; Payne 2015, 2016; Zubala \& Karkou, 2014).

Both recognize the importance of unconscious, and non-conscious dynamics ${ }^{1}$ (early preverbal dynamics) and understand that access to the exploration of the unconscious and

The term nonconscious is used in neuroscience and psychology to denote processes experienced and observed in physical actions and feelings. These processes do not involve spoken language and symbolic thinking (Rustin, 2013) and are developed in early infancy preverbally (but not exclusively). "Implicit knowing is nonconscious" (Stern, 2004, p 116). Implicit/procedural knowing is, however, potentially knowable and may become conscious through bringing attention to the feelings and physical movements (Stern, 2004, Beebe and Lachman, 2014). This cluster of psychotherapy authors uses the term nonconscious to differentiate it from Freud's unconscious and unconscious repressed material. Heller (2012) also emphasises that a "nonconscious event....influences the periphery of out inner atmosphere, but not as something that can be grasped in an explicit way through introspection" (Heller, 2012, p. 354). 
nonconscious processes is through the body. The term nonconscious is used following Stern (2004), Rustin (2013), and Beebe and Lachmann (2014).

Furthermore, in BP and

DMP the psychotherapist attunes to the client's non-verbal and/or expressive movement (Westland, 2015a; Zubala \& Karkou, 2014; Sletvold, 2014; Payne, 1992, 2006b; Carroll, 2009; Levy, 1988) to build the therapeutic alliance and achieve therapeutic change. In DMP, however, the emphasis is on improvised, creative, aesthetic and interpersonal engagement in movement.

\section{Professional settings for practice in the UK}

DMP and BP in the UK are part of psychotherapeutic services in the private and public sectors and both are accountable to a mixture of national statutory and approved voluntary regulatory frameworks. For various historical reasons, DMP and BP work contexts evolved differently however. Currently, BP is mostly associated with the private sector and longer term work whereas DMP practice is often in the public health sector.

Training programmes have differing recognition, DMP is usually University-based at Masters level whereas all but one BP training is in the private sector thus without academic recognition (unlike in the USA). Both disciplines however work with complex cases and have contributed to the literature. In BP, for example, anorexia (Sella, 2003); borderline personality disorder (Warnecke, 2009) and post-traumatic stress disorder/trauma (Heitzler, 2009; Ogden et al., 2006; Rothschild, 2000). BP is also recognised for its in-depth work with stressful and traumatic pre-verbal development (early attachments disruptions) (Bentzen, 2015, Kignel 2012, Ogden \& Fisher, 2015).

In DMP, for example, the pre-verbal is also frequently focused upon within the field of trauma (Gray 2001, 2002; Mills \& Daniluk, 2002; Moore, 2006; Kornblum \& Halsten, 2006; MacDonald, 2006; Singer, 2006; Koch \& Harvey 2012). Studies in the practice of DMP and eating disorders have been documented, see Kruger \& Schofield (1986); Naitove (1986); 
Totenbier (1995); Lausberg, von Wietersheim and Feiereis (1996); and Pylvainen (2003). Furthermore, there are three Cochrane Systematic Reviews for DMP and schizophrenia (Ren \& Xia 2013), cancer care (Bradt, Shim \& Goodill, 2015), depression (Meekums, Karkou \& Nelson, 2015), and dementia (Karkou \& Meekums, 2014).

\section{Some important themes in DMP and BP}

\section{Embodiment}

Embodiment and embodied cognition underpins BP and DMP and both fields draw on philosophy and cognitive science. Influential writers include Merleau-Ponty (1945) (phenomenology); Gallagher (2005) (philosophy of mind, cognitive science, hermeneutics); Varela, Thompson, and Rosch (1993) embodied cognition and Damasio (2004) embodied feelings and somatic marker hypothesis. There has been a steady flow of research on the psychosomatic properties of biological systems (for example, the sensory-motor system, autonomic nervous system, and immune system) demonstrating interconnectedness and continuity between internal body processes, cognitive processes, and external interpersonal meanings and influences.

Varela et al (1993) have extended the discussion within phenomenology and cognitive neurosciences suggesting that Buddhist philosophy and meditation practices offer frameworks for "skilful and disciplined examination of experience" (p. xviii). Their observations have built pathways towards some forms of BP and DMP which have been by the same token influenced by Eastern psychology and mindfulness meditation practices (Aposhyan, 2004; Kurtz, 1990; Ogden et al, 2006; Weiss, Johanson, \& Monda, 2015; Westland, 2015a). Within DMP Payne (2016), for example, describes mindful movement as bodymindfulness and many DMP practitioners draw heavily upon approaches to DMP such as authentic movement (Whitehouse, 1979) that is influenced by Jungian and Eastern thinking. These ideas and practices expand the discussion around embodiment beyond what phenomenology and current scientific discoveries can offer.

Payne $(2015,2016)$ designed a model from elements of DMP and authentic movement 
termed The BodyMind Approach ${ }^{\mathrm{TM}}$ specifically for NHS patients in primary care experiencing persistent bodily sensory distress without a medical explanation (medically unexplained symptoms). Bodily symptoms for which physicians found no medical or hereditary cause were a focus for the early psychoanalytic movement such as Janet, (1889), Groddeck, (1983) and Ferenczi, (1952). Although most of the psychoanalytic field came to undervalue this connection, these early advances in understanding connections between body, emotional and mental states, informed and supported BP and DMP in developing clinical theory and practice of embodiment dynamics. Staunton (2002) for example writes:

the fundamental premise in body psychotherapy is that core beliefs are embodied, and that until we begin to experience the pain held in them directly through our bodies they will continue to run our lives, even if we mentally understand them (p.4).

Furthermore, Fuchs (2003) describes his concept of embodied personality structure:

The shy, submissive attitude of a dependent person, her soft voice, childlike facial expression, her indulgence and anxiousness belong to an integrated pattern of expression and posture that is an essential part of the personality. Our basic attitudes, our typical reactions and relational patterns, in one word: our personality itself is based on the memory of the body. (ibid, p. 5)

DMP and BP focus on different aspects of the client's body-in-process. DMP evolved around attention to movement and motility and continues to maintain a primary focus on improvised, spontaneous and symbolic movement in the therapeutic relationship. In contrast BP has historically maintained a particular focus on autonomic nervous system activity, breathing, and muscular armouring patterns for the regulation of emotions, energy and physiology and emphasizes the client's non-conscious movements. The body of the therapist has also become included in clinical perspectives (Rolef Ben-Shahar, 2014, Warnecke 2011).

Overall there is a strong congruence between BP and DMP and the significance they give to embodied experiences in clinical practice, whether in embodied thoughts, feelings, sensations or imaginings. For both fields, body experiences are central and include discussion on:

- immediate body-in-process experiences, 
- body as the basis for reality testing,

- body experiences as the pre-condition for the development of a sense of self,

- body as the manifestation and symbolic representative of cultural and sociological identity,

- body as symbol and metaphor,

- body as memory,

- body as a symptom-expression of psychological processes

- body as a therapeutically utilizable instrument (Totton, 2003; Broom 2007; Koch \& Fuchs 2011).

\section{The Psychotherapeutic Relationship}

Relationship is at the heart of any type of psychotherapy and for both BP and DMP the emphasis is upon embodied psychotherapeutic relationships (Totton 2015), and often privileging non-verbal and relatively right brain to right brain interactions (Schore 2003a, 2003b, 2011, Marks-Tarlow, 2012), alongside verbal interactions. BP and DMP also recognise the uniqueness of each psychotherapy process which is co-created by the therapeutic dyad. Here the client and therapist bring their personal histories, attachment patterns, life experiences, and projections, and for the DMP their movement. For both practices the therapist brings their training. The process is individual for each dyad or group. Indeed, research on body psychotherapy concluded that what happens in the consulting room is highly complex and "cannot be reduced to one particular formula" (Hoskins, 2014, p. 44).

To add to this complexity, Karkou and Sanderson (2006) in their discussion of psychotherapeutic relationships within DMP observed that context-specific dance expands the dyadic psychotherapeutic relationship to a triangular relationship that not only supports what is happening between the psychotherapist and the client, but also encourages clients to engage with dance and movement as a third corner of the relationship. Body psychotherapists generally give less significance to relating through creative media and 
triangular "three-way relating" as described by art psychotherapist and Jungian analyst, Schaverien (1995). This three-way-relating is not to be confused with thirdness as referred to in the psychoanalytic 'third'. However, the possibilities of triangular relationship have been recognised by body psychotherapist Westland (2015a) in terms of where attention is placed therapeutically and which particular relationship is in the foreground. Boadella (1992) has also contributed to this discussion.

BP and DMP are both familiar with a framework for thinking about therapeutic relationships as proposed by Clarkson (1994). Although quite an old model, it provides common ground for discussion. Soth (1993) for example observed that Clarkson's five modes of relating describes spaces between client and therapist. Adapting Clarkson, Karkou and Sanderson (2006), suggest that in DMP, I- thou relationships (Buber, 1958) may take the shape of an artistic affiliation where both psychotherapist and client co-create therapeutically meaningful movement material. This is facilitated through the active engagement of both client and psychotherapist. A mutual reflection on this engagement may also take place, with an emphasis of understanding the meaning of their co-created dance for the benefit of the client. Concepts such as empathetic attunement, kinaesthetic empathy and the associated method of mirroring are extensively discussed within DMP literature as core ingredients not only of a therapeutic alliance but also as a way of understanding and acknowledging the client (see further discussion on this in the 'methods' below).

Within BP the understanding of the therapeutic relationship has evolved over the last 20 years. Inspired by Guggenbuhl-Craig (1971), Soth (2009) elaborated on the concept of the wounded healer and embraced, from analytical psychology, the idea that both client and therapist were changed by the therapeutic process; a concept also highly influential within DMP theory and practice. And similar to DMP, BP took on influences from Gestalt therapy (Perls, Hefferline \& Goodman, 1951), which enabled body psychotherapists to revisit Reich's ideas about contact between therapist and client (Boadella, 1987, Rosenberg, Rand \& Asay, 1985). 
Shifting away from the 'I-thou' relationship, Karkou and Sanderson (2006) argue that in DMP the transferential relationship (Clarkson, 1994) can be a relevant relationship with which to engage taking various forms. For example, it can involve a client developing transferential responses to a particular movement or dance in which they were engaged. The psychotherapist may respond to a particular dance created by the client countertransferentially. This offers the possibility to expand a dyadic transference to a triangular formation. When a dance is not co-created, the client may be the creator of a particular movement/dance as is the case with authentic movement (Payne, 2006c; Adler, 2002; Whitehouse, 1979) for example, encouraging transferential material to surface in the presence of the psychotherapist as a witness.

Within BP transferential dynamics are often thought about, including projective identification (Boadella, 1982, Soth 2009, Warnecke, 2009). Interestingly both fields discuss the relevance of somatic transference and counter-transference. In BP, Westland (2015a) refers to somatic resonance and reaction, while in DMP, Dosamantes- Beaudry (2007), Lewis (1992) and Meekums (2008) explore these concepts with diverse client populations. Whilst there are multiple therapeutic aspects that contribute to change and healing, it is now recognised that change also happens through transforming implicit memories at nonconscious levels (Lyons-Ruth, 1998; Marks-Tarlow, 2013; Schore, 2011; Stern, 2004). In tandem with this is the recognition that relational problems stemming from early insecure and traumatic attachments (prior to spoken language) require more than formulaic interactions. What is critical for change is "...how to implicitly and subjectively be with the patient...." (Schore, 2011, pp. 94-95, emphasis in original). Both BP and DMP would concur with these statements.

Both BP and DMP have also drawn upon concepts relating to intersubjectivity and attunement stemming from infant development research such as Stern (1985) concerned with the infant's interconnected perceptual, affective, and motoric strategies. Trevarthan's (2005) research on proto-conversations and musicality between parent and infant, and 
Beebe and Lachman $(2002 ; 2014)$ on the dyadic systems creating connections between infant research and therapeutic experiences also underpin both practices.

Since the 1980s BP in the UK has engaged with attachment theories and psychodynamic ideas. Soth (1994) and Boadella (1997b) observed that therapeutic interactions are intersubjective at their core. Other BPs reached analogous conclusions through the influence of Buddhist psychology, and concluded that humans are interconnected (Ogden et al, 2006; Westland, 2015a).

Although body psychotherapists refer to the medical model less nowadays, remnants of it abide when, for example, psychotherapists describe doing bodywork. Soth (2009) challenged this medical thinking and the pitfalls of interactions intending to remediate clients' pathology, which, often inadvertently, replicated the body-mind splits practitioners were seeking to re-dress. Rare references to such ways of relating can be found in DMP, even where DMP is practised in hospitals with models coined as medical DMP to reflect this type of work (Goodill 2005; Serlin 2000).

The BP therapeutic relationship is described as collaborative (Westland, 2015a) and engaging the co-operation of the unconscious (Kurtz, 1990, 2015) with an intention of non-violence and loving presence. Westland (2015a) describes the significance of establishing safety and bringing qualities of clarity, compassion and spaciousness to the therapeutic dyad. Staying with the theme of complexity and the multi-layered dimensions of BP, Boadella reminds us to look "beyond the psychodynamic level of the therapeutic relationship, important as it is..." and of the developmental, the real, the energetic, the imaginal and the contractual relationships, and "beyond all that, there is the silent being-together at an almost meditative level of tuning in,...a genuine tuning in of the heart" (Boadella, 2015, pp. 202-203).

Contemporary BP describes a mutual relationship of client and psychotherapist, uniquely cocreated in a moment by moment body-in-process dialogue at multiple and simultaneous levels of consciousness, which includes the transference relationship (Warnecke, 2011). Relational BP describes therapeutic relationships in terms of two person rather one person relating (Rolef Ben-Shahar, 2014) and, as psychotherapist and client interact with each other, "a third shared 
reality is born" (Totton, 2014, p. 44), a co-created "entity which assumes certain autonomic characteristics" (Rolef Ben-Shahar, 2014, p. 102). This is not to be confused with thirdness as referred to in the psychoanalytic 'third'.

Within the multiplicity of therapeutic relationships possible with BP, Carroll (2005) argues the importance of the rhythms of relating in which contact occurs. The idea of rhythm, familiar in DMP not only metaphorically but also literally, can be a very important common way to conceptualise how an embodied therapeutic relationship can develop and change during the course of therapy. Engaging in this 'dance' and being aware of when and how rhythms change (or when the therapist and the client are out of synch) can be potentially relevant and useful ways of thinking about therapeutic relationships in both modalities.

\section{Theoretical foundations}

Current DMP practice draws upon significant artistic/creative and developmental aspects that stem from Laban and his students (Payne, 1990; 1992; 2006b; Karkou \& Sanderson, 2006; Zubala \& Karkou, 2014) as well as employing Laban Movement Analysis.

Furthermore, it draws upon diverse influences, creating unique but recognizable practices that fall under particular psychotherapeutic frameworks. In a recent survey of practitioners, psychoanalytic/psychodynamic frameworks (Bowlby, 1969; Freud, 1953; Jung, 1990; Klein, 1975; Winnicott, 1971) are the most popular influencers when dance movement psychotherapists reflect on their practice. Within clinical sessions, they also draw heavily upon humanistic psychology including person-centred therapy (Rogers, 1951) and Gestalt therapy (ibid). Feldman (2016) for example, makes connections between BP and DMP from a Gestalt therapy perspective, while Karkou and Sanderson (2006) argue that the model of Chace (Chaiklin \& Schmais, 1986) falls neatly under a humanistic rationale. Eclectic and integrative psychotherapeutic frames (Abram, 1992; Garfield, 1980, Thorne, 1967) are also employed (Karkou \& Sanderson, 2006; Payne, 1994; Zubala \& Karkou, 2014). Integrative models in particular lend themselves readily to the field as documented by Payne (1992; 
2006b) and Karkou and Sanderson (2006). Behavioural ideas, especially learning theory (Skinner, 1953) are employed as presented by, for example, North (1972), and in Karkou \& Sanderson, (2006). Influences from postmodern approaches to psychotherapy such as social constructionism (McNamee \& Gergen, 1992) and narrative therapy (White \& Epston, 1990) can be found in contemporary DMP practice, for example, Allegranti (2011).

Comparably, contemporary BP has grown since its initial development. Reich's (1949) observation of the build-up of psycho-physiological tension which formed the basis for his groundbreaking theories on character, muscular armouring and sexuality. In the 1970s, Reich's (1949) understanding of inhibiting or binding dynamics and catharsis for selfexpression in the therapeutic relationship expanded to also include the formative and selforganizing principles of bodymind.

Thus BP has been reformulated as a gradual re-organization of the bodymind arising out of the dynamics between client and psychotherapist (Carroll, 2005; Ogden et al., 2006; Weiss, Johanson \& Monda, 2015). Alongside the recognition that self and ego functions rely heavily on complex sensory motor organization (Boadella, 1992; 1997a, Boyesen; 1980, Keleman, 1985; Stauffer, 2010). Insights from perinatal and infant development paved the way for the recognition that hypo-tone (Boadella, 1987; Holm-Brantbjerg, 2015, Marcher \& Fich, 2010) can be as limiting as excessive restrictive (hyper-tone) armoring patterns. This recognition has been taken into work with traumatised clients (Rothschild, 2000). From the 1990s, DMP and BP have been revised in the light of advances in the understanding of infant development and how change occurs (Beebe \& Lachmann, 2002, 2014; Stern, 1985). A number of associated fields of cognitive/neuropsychological sciences (Damasio, 1994; Schore, 1994) inform key theoretical and clinical assumptions and principles as well the modes of therapeutic action in both DMP and BP. These advances have impacted not only BP and DMP, but led to revisions and new developments in psychoanalysis which have enabled some rapprochement between BP and psychoanalysis, especially, when BP entered into dialogue with relational psychotherapy (Mitchell, 1988). Body psychotherapists contributing to the relational discourse include 
Asheri (2009); Carroll (2009); Cornell (2015); Nolan (2012); Rolef Ben-Shahar, 2014; Sletvold (2014); Soth (2009); Totton (1998, 2014); Warnecke $(2009,2011)$.

Likewise, DMP has maintained a strong connection to psychoanalytic/psychodynamic thinking and publications discuss intersubjective aspects of the work (Samaritter, 2015). Furthermore, Chace's widely used interactive approach from the USA, has been revisited for particular contributions that this approach makes to intersubjective experiences in groups. Additional links between DMP and relational psychoanalysis have not, as yet, been explored. This may be an interesting area for dance movement psychotherapists to consider as a future theoretical development.

\section{Techniques and Methods}

In DMP methods are often employed within groups although for complex clients such as those with autism or profound learning difficulties individual sessions may be indicated. Group methods include the Chacian circle (Chaiklin \& Schmais, 1986) and methods that follow behavioural principles that have emerged from dance practices. Chace's interactive way of working encourages the use of mirroring, rhythm, synchronous movement, symbolic movement together in a group, often within a circle formation usually with music. After the therapist has led for a while they invite members of the group to take the leadership while the group reflects the leader's movement. The movement content is improvisatory and the work tends to be interpersonal and collaborative (Wengrower, 2009).

In individual sessions when the psychotherapist mirrors the client's movement, s/he often uses improvised movement responses. Kinaesthetic empathic responsiveness to a client's movement repertoire is essential to developing a therapeutic alliance (Samaritter \& Payne, 2013). Synchronous, effortful movement together nurtures the embodied relationship (Tarr, Launay, Cohen \& Dunbar, 2015) and provides the therapist with a body felt-sense of the client's actions, emotions and sensory experiences facilitated by mirror neurones and embodied simulation (Berrol, 2006; Gallese \& Sinigaglia, 2011). Attunement (connecting in 
rhythm) and adjustment (connecting in shape) can be part of the experience of mirroring (Kestenberg-Amighi; Loman, Lewis, Sossin, 1999). This could develop into non-verbal dialogues which can be followed enabling explorations and working through of clients' presenting issues (Meekums, Karkou \& Nelson, 2015).

Psychodynamically informed DMP may focus on the biographical history of the client/s attending to conflicts and aiming to achieve insights (Penfield, 2006; Karkou \& Sanderson, 2006; Siegel, 1984). Others may use practices developed from authentic movement. Whether practicing in a group or individually encouraging kinaesthetic awareness, working with polarities, celebrating active imagination within the body experience, moving and witnessing within a therapeutic relationship is always informed by embodied presence (Payne 2006c). The therapist might invite the client to explore/expand on a movement noticed by the therapist, perhaps amplifying or contrasting it, with eyes closed, either in a movement space or chair. This can involve connections to the client's history in therapy, or before it, and give a different perspective or validate the client's embodied experience. Sherborne's (2001) developmental movement activities, derived from Laban dance, for example, are often used to support development as are methods stemming from Kestenberg movement profiling (KestenbergAmighi, et al; 1999) and Bartenieff and Lewis (1980).

Directive methods are in common usage within DMP practice in the UK as developed within the context of school-based Laban-informed creative dance practice (Eke \& Gent, 2010; Karkou \& Sanderson, 2006). Within school environments, developmentally-appropriate tasks and experiences can also be offered as opportunities for clients to revisit earlier developmental stages and/or progress to the next developmental milestone (Bannerman-Haig, 2006).

Modern approaches to DMP practice may use choreographic structures and devices found in postmodern dance and psychotherapy. For example, practitioners may focus on mininarratives, relying on local meaning and encouraging change through interrupting existing fixed stories and power relationships (Karkou \& Lycouris, 2011). Next to them, tools such as role playing, the creative use of props and the use of other artistic media including music and visual arts are often used within DMP practice, serving particular psychotherapeutic purposes 
(such as transitional objects) appropriate to the individual, relevant to the relationship and specific to the issues addressed and the overall needs of the clients.

BP consists of numerous forms and this plurality is particularly apparent when looking at methodologies and psychotherapeutic techniques, many of which are specific to the particular form of BP that developed them. BP techniques are intended as vehicles for exploration (Boening, Southwell \& Westland, 2012). They aim to reveal the psychobiological relational dynamic(s) of the client-therapist dyad. Body psychotherapists will commonly adapt techniques to the individual client and pay particular attention to the continuum of involuntary and voluntary motor activities (such as a little more or a little less).

Three realms of relating to the body of the client can be distinguished in BP:

1. Being with, with attention, presence and attunement to self and other (Kurtz, 2015).

2. Observing what is experienced, articulating observations and inviting a client to explore and experience phenomena that have caught the attention of the psychotherapists, for example, explorations of internal embodied experience and movement (Sletvold, 2014).

3. Bodily activities may focus on sensory-motor, respiration, and tactile contact experiences (both self-contact and interpersonal contact) or invite free association of the body found in Vegetotherapy (Boyesen, 2006)

Of particular importance is the perceptual-sensual awakening potential of movement and the depth and intensity of insight it may afford. Movements and respiration may be utilized to intensify sensory perception and help a client to connect to their immediate experience (Warnecke, 2012). Methods may be chosen as access points for the exploration of domains of experience, either well developed or under-developed aspects of a client, which are revealed in the therapeutic relationship. Nolan (2012) has mapped five modes of experience and function; body sensations, emotions, cognition, imagination and motor activity. These indicate intrapersonal and interpersonal possibilities and limitations. Thus the imagination and imagery may be employed with clients who connect with images, but their jointly created repertoire extend gradually to include more of the other modes. 
BP uses symbolic aspects of embodiment; a client's dreams or spoken narratives may contain body-based elements to attend to. Likewise, objects such as strings, chairs, cushions or objects may get assigned symbolic meaning to deepen experiences and creatively explore them, often through play and make believe.

BP has an array of active methods such as grounding exercises, exercises to develop body awareness and exaggerating a movement or gesture to amplify feelings, and resistance exercises to strengthen a sense of self. Contact through touch, and including biodynamic massage is also included as well as the use of creative media such as the use of art materials to communicate and express the client's inner world. However, a technique learned in training over time becomes a honed skill after repeated practice and experience (Kurtz, 1990). These skills become embedded in the being of the psychotherapist and emerge intuitively and spontaneously in interactions with clients (Westland, 2015a).

Some of the above BP methods are similar to, and in some cases central to, DMP practice such as grounding, breathing and centering exercises, creative media, symbolic work, imagery, use of space and the role of dreams. Others, like touch, may be more widely used within BP (Asheri, 2009; Westland, 2015b) than in DMP. However, there are a number of practitioners within the DMP discipline who bring touch into their practice due to other training, for example, in contact improvisation (Paxton, 2008), massage or Body-Mind Centering® (Bainbridge-Cohen, 2012). It would be also fair to say that in DMP practice, theoretical principles, client needs and the type of relationship between the therapist and the client determine what takes place in the session which certainly parallels BP practice.

\section{Conclusion}

From the evidence above it is apparent that BP and DMP employ a compatible and often overlapping psycho-physiological understanding of the human organism and the deeply personal realm of the individual. BP and DMP theories of psychological change appear correspondingly attuned. It is equally evident however, that both therapeutic fields carry distinct and significant differences that cannot be ignored, in practice they look and feel very 
different. This article has focused on comparisons and similarities between DMP and BP. Further work is required to sharpen the differences between the two professions. This will be the topic of a future article. Further discussion around this topic and empirical studies emerging from curiosity about the associated but distinctive practices can only inform, strengthen and enrich the two fields. On the one hand professional boundaries remain intact, while on the other practice is advanced and clients receive the benefits of well-informed embodied approaches.

\section{References}

Abram J (1992) Individual psychotherapy trainings: A guide. London: Free Association Books.

Adler, J. (2002). Offering from the conscious body: The discipline of Authentic Movement. Vermont: Inner traditions.

Allegranti, B. (2011). Embodied performances: Sexuality, gender, bodies. New York:

Palgrave Macmillan. Accompanied by 60 mins of film drawing from practice-based research. Aposhyan, S. (2004). Body-Mind Psychotherapy. Principles, Techniques and Practical Applications. New York: W. W. Norton.

Asheri, S. (2009). To touch or not to touch: a relational body psychotherapy perspective. In Hartley, L. (Ed.), Contemporary body psychotherapy, the Chiron approach (pp.106-120). London: Routledge.

Bainbridge-Cohen B (2012) ( $3^{\text {rd }}$ ed) Sensing, Feeling and Action: The Experiential Anatomy of Body-Mind Centering ${ }^{\circledR}$. US: North Atlantic Books.

Bartenieff, I., Lewis, D. (1980) Body movement - Coping with the environment. New York: Routledge.

Beebe, B. and Lachmann, F. M. (2014). The Origins of Attachment. Infant Research and Adult Treatment. London: Routledge. 
Bentzen, M. (2015). Dances of connection: Neuro-affective developmental psychology and attachment theory. International Journal of Body, Movement and Dance in Psychotherapy, $10,4,211-226$

Beebe, B. and Lachmann, F. M. (2002). Infant research and adult treatment, co-constructing interactions. London: Analytic Press.

Beebe, B. and Lachmann, F. M. (2014). The origins of attachment. Infant research and adult treatment. London: Routledge.

Berrol, C. F. (1992). The neurophysiologic basis of the mind-body connection in dance movement therapy. American Journal of Dance Therapy, 14, 1: 19-29.

Berrol C F (2006) Neuroscience meets dance/movement therapy: Mirror neurons, the therapeutic process and empathy The Arts in Psychotherapy 33: 302-315.

Boadella, D. (1982). Transference, Resonance and Interference. Journal of Biodynamic Psychology. 3, 54-73.

Boadella, D. (1987). Lifestreams. An introduction to Biosynthesis. London: Routledge, and Kegan Paul.

Boadella, D. (1992). Science, Nature and Biosynthesis - General scientific principles of somatic psychotherapy. Energy \& Character, 23, 5: 2-60.

Boadella, D. (1997a). Embodiment in the therapeutic relationship. International Journal of Psychotherapy, 2, 1: 31-44

Boadella, D. (1997b). Awakening sensibility, recovering motility: psycho-physical synthesis at the foundations of body-psychotherapy: the 100-year legacy of Pierre Janet (1859-1947). International Journal of Psychotherapy, 2, 1: 45-57.

Boadella, D. (2015). Soma Semantics: Meaning of the Body. In: G Marlock, H Weiss, (Eds) with C Young, and M Soth, The Handbook of Body Psychotherapy and Somatic Psychology. (pp.197-204). Berkeley: North Atlantic.

Boening, M., Southwell, C. \& Westland, G. (2012). UK Body Psychotherapy Competencies. Retrieved from http://www.eabp.org/forum-body-psychotherapy-competencies.php and http://www.cbpc.org.uk/ 
Boyesen, G. (1980). Biodynamic Psychology. The Collected Papers. Volume 1 and 2. London: Biodynamic Psychology Publications.

Boyesen, G. (2006). How I developed biodynamic psychotherapy. In J. Corrigall, H. Payne \& H. Wilkinson (Eds.). About a body: working with the embodied mind in psychotherapy (pp. 132-139). London: Routledge.

Bradt, J., Shim, M. \& Goodill, S.W. (2015). Dance/movement therapy for improving psychological and physical outcomes in cancer patients. Cochrane Database of Systematic Reviews 2015, Issue 1. Art. No.: CD007103. DOI: 10.1002/14651858.CD007103.pub3.

Buber, M. (1958). I and thou. (Trans. R.G. Smith). New York: Charles Scribner's.

Broom, B. (2007). Meaningful disease. London: Karnac.

Carroll, R. (2005). Rhythm, reorientation, reversal: deep reorganization of the self in Psychotherapy. In: J. Ryan, (Ed). How Does Psychotherapy Work? London: Karnac. (pp. 85-112).

Carroll, R. (2009). Self-Regulation at the heart of body psychotherapy. In: L Hartley (Ed.). Contemporary Body Psychotherapy: The Chiron Approach (pp. 89-105). London: Routledge.

Chaiklin S and Schmais D (1986) The Chase Approach to Dance Therapy, In: P. Lewis (Ed.) Theoretical Approaches in Dance/Movement Therapy, Vol 1. Iona: Kendall/Hunt, (pp 17-36). Chodorow, J. (1991). Dance Therapy and depth psychology: The moving imagination. London: Routledge.

Clarkson, P. (1999). Eclectic, integrative, and integrating psychotherapy or beyond schoolism. In: S. Palmer \& R. Woolfe (Eds.) Integrative and eclectic counselling and psychotherapy (pp. 305-314). London: Sage.

Cornell, W. F. (2015). Somatic experience in psychoanalysis and psychotherapy: in the expressive language of the living. Hove: Routledge.

Damasio, A. (1994). Descartes' error, emotion, reason and the human brain. London: Picador. 
Dosamantes-Beaudry, I (2007) Somatic Transference and Countertransference in Psychoanalytic Intersubjective Dance/Movement Therapy. American Journal of Dance Therapy 29, 2:73-89. DOI: 10.1007/s10465-007-9035-6

Dychtwald, K (1986) Bodymind. 2nd Revised edition. Jeremy P Tarcher Publisher EABP (1991). Definition of the work of a Body Psychotherapist. http://www.eabp.org/aboutdefinition-body-psychotherapist.php (accessed on 12/11/2015)

Eke, L \& Gent AM (2010) Working with withdrawn adolescents as a moving experience: a community resourced project exploring the usefulness of group dance movement psychotherapy within a school setting. International Journal of Body, Movement and Dance in Psychotherapy, 5, 1, 45-57.

Eiden, B. (2002). Application of post-Reichian body psychotherapy: a Chiron perspective. In T. Staunton (Ed.). Body psychotherapy (pp. 27-55). Hove: Brunner-Routledge.

Ferenczi, S. (1952). Further contributions to the theory and technique of psycho-analysis. In: J Rickman (Ed) Further contributions to the theory and techniques of psychoanalysis. New York: Basic Books.

Gallagher, S. (2005). How the body shapes the mind. Oxford: Oxford University Press. Garfield S L (1980) Psychotherapy: An eclectic approach. New York: Wiley. Goodill, S (2009) An introduction to medical dance/movement therapy. London: Jessica Kingsley

Guggenbuhl-Craig, A. (1971). Power in the Helping Profession, Spring Pubs.

Freud S (1953) Three Essays on the Theory of Sexuality. In J Strachey (Ed) The Complete Psychological Works of Freud, 7, London: Hogarth.

Fuchs, T (2003) The memory of the body. : www.klinikum.uniheidelberg.de/fileadmin/zpm/psychatrie/ppp2004/manuskript/fuchs.pdf Accessed 7.12.15

Gallese V. \& Sinigaglia C. (2011). How the body in action shapes the self. Journal of Consciousness Studies, 18, 7-8:117-43. 
Gray, A. E. L. (2001). The Body Remembers: Dance/Movement Therapy with an Adult Survivor of Torture. American Journal of Dance Therapy, 23, 1:29-43.

Gray, A. E. L. (2002). The Body as Voice: Somatic Psychology and Dance/ Movement Therapy with Survivors of War and Torture. Connections, 3, 2: 2-4.

Groddeck, G. (1983). Disease as a symbol. Fonts for Psychosomatics. In: H Siefert (Ed). Illness as symbol, psychosomatic papers. Frankfurt: Fischer.

Hartley, L. (2009). (Ed.) Contemporary body psychotherapy: The Chiron approach. London: Routledge.

Heitzler, M. (2009). Towards an integrative model of trauma therapy. In L. Hartley (Ed.), Contemporary body psychotherapy: The Chiron approach (pp 177-193). London: Routledge. Heller, M. C. (2012). Body psychotherapy: History, concepts and methods. New York: W.W. Norton.

Holm Brantbjerg, M. (2015). Integrating polarities through regulation of hypo- and hyper-responses to stress - An experiential keynote. International Journal of Body, Movement and Dance in Psychotherapy, 10, 1: 39-50

Hoskins, R. (2014) An exploration of the meaning of working with the body for body psychotherapists. A dissertation in partial fulfilment of the requirement of MA, Anglia Ruskin University (unpublished).

Janet, P. (1889). Psychological automatisms. Félix Alcan. New edition: Société Pierre Janet, Paris, 1973.

Karkou, V. \& Lycouris, S. (2011). Relationships between artistic and therapeutic aspects of dance: Meeting points of a dance movement psychotherapist and a choreographer, Presentation at The Arts Practice Conference, Edinburgh.

Karkou V and Sanderson P (2006) Arts Therapies: A Research-Based Map of the Field. Edinburgh: Elsevier. 
Karkou, V. \& Meekums, B. (2014). Dance movement therapy for dementia (Protocol). Cochrane Database of Systematic Reviews, Issue 3. Art. No.: CD011022. DOI: 10.1002/14651858.CD011022.

Karkou V, Oliver S and Lycouris S (in preparation) (Eds.) The Oxford Handbook of Dance and Wellbeing. New York: Oxford University Press.

Karkou V; Fresquez C; Erber B and Galon, Ce (in preparation). Trauma, Women and Therapy in the Community: Dances of Protection and Change, In: V Karkou, S Oliver and S Lycouris (Eds.) The Oxford Handbook of Dance and Wellbeing. New York: Oxford University Press.

Keleman, S. (1985). Emotional anatomy. Berkeley, CA: Center Press.

Kestenberg-Amighi J; Loman S; Lewis P; Sossin KM (1999) Developmental and clinical perspectives of the Kestenberg movement profile. New York: Routledge Kignel, R. (2012). The field of semiotics as applied to body psychotherapy. International Journal of Body, Movement and Dance in Psychotherapy, 7, 1: 23-37

Krantz, A. M. (2012). Let the body speak: Commentary on paper by Jon Sletvold. Psychoanalytic Dialogues: The International Journal of Relational Perspectives, 22, 4: 437448.

Koch, S; Harvey S (2012) Dance/movement therapy with traumatized dissociative patients In: T Fuchs, S Koch; Summa M; Müller C; Body memory, metaphor and movement. (pp 369385); John Benjamins Publisher Koch, S., Jünger, J., Kelbel, J., Kolter, A., Sattel, H. \& Fuchs, T. (submitted for publication). (Dis-)Embodiment in schizophrenia: Effects of mirroring on self-experience, empathy and wellbeing. In V. Karkou, S. Oliver \& S. Lycouris (Eds.) The Oxford Handbook of Dance and Wellbeing. New York: Oxford University Press.

Koch, S. C., \& Fuchs, T. (2011). Embodied arts therapies. The Arts in Psychotherapy, 38, 276-280. 
Kornblum, R. \& Halsten, R. L. (2006). In-school dance/movement therapy for traumatized children. In S. Brooks (Ed.), Creative Arts Therapies Manual. Springfield, IL: Charles C. Thomas.

Kruger, D., \& Schofield, E. (1986). Dance/movement therapy of eating disordered patients: A model. American Journal of Dance Therapy, 13, 323-331.

Kuhn, T. (1970). The Structure of Scientific Revolutions. Chicago: University of Chicago Press.

Kurtz, R. (1990). Body-centered psychotherapy. The Hakomi method. Menocino, CA: Life Rhythm.

Kurtz, R. (2015). The essential method. In: H. Weiss, G. Johanson \& L. Monda (Eds.), Hakomi mindfulness-centered somatic psychotherapy: A guide to theory and practice (pp.1933). Berkeley: North Atlantic Books.

Laban, R. and Lawrence, F. C. (1974). Effort. London: MacDonald and Evans.

Lausberg H, von Wietersheim J, \& Feiereis H. (1996). Movement behavior of patients with eating disorders and inflammatory bowel disease: A controlled study. Psychotherapy and Psychosomatics, 65, 272-276.

Levy, F. J. (1988). Dance movement therapy: A healing art. Virginia: American Alliance for Health, Physical Education, Recreation and Dance.

Lewis, P. P. (1992). The creative arts in transference/countertransference relationships. The Arts in Psychotherapy, 19, 5: 317-323.

Lowen, A. (1975). Bioenergetics. New York: Penguin.

Lyons-Ruth, K. (1998). Implicit relational knowing: its role in development and psychoanalytic treatment. Infant Mental Health Journal, 19, 282-289.

MacDonald, J. (2006). Dancing with demons: Dance movement therapy and complex posttraumatic stress disorder. In H. Payne (ed.) Dance movement therapy: theory, research and practice. (pp 49-70). London and New York: Routledge Marcher, L, and Fich, S. (2010). Body Encyclopaedia. A Guide to the Psychological Functions of the Muscular System. Berkeley, CA: North Atlantic Books. 
Marks-Tarlow, T. (2012). Clinical intuition in psychotherapy: The neurobiology of embodied response. New York: W. W. Norton.

Marlock, G. and Weiss, H. (2015). The Field of Body Psychotherapy. In Marlock, G. and Weiss, H. with Young, C. and Soth, M. The Handbook of Body Psychotherapy and Somatic Psychology pp. 1-17. Berkeley: North Atlantic Books.

McNamee, S. \& Gergen, K. J. (Eds.) (1992). Therapy as social construction. London: Sage. Meekums, B. (2008). Spontaneous symbolism in clinical supervision. In H. Payne (ed) Supervision of Dance Movement Psychotherapy. London and New York: Routledge, pp 1832.

Merleau-Ponty, M. (1965). Phenomenology of Perception. Trans: Colin Smith. London: Routledge

Mills, L., \& Daniluk, J. (2002). Her body speaks: The experience of dance therapy for women survivors of child sexual abuse. Journal of Counseling \& Development, 80, 1: 77-85 Mitchell, S. A. (1988) Relational concepts in psychoanalysis: An integration. London: Harvard University Press.

Moore, C. (2006). Dance Movement Therapy in the light of Trauma: Research findings of a multidisciplinary project. In S.C. Koch \& I. Bräuninger (Eds.). Advances in Dance/Movement Therapy. Theoretical Perspectives and Empirical Research. Berlin: Logos Naitove, C. (1986). Life's but a walking shadow: Treating anorexia nervosa and bulimia. The Arts in Psychotherapy, 13, 107-119.

Nolan, P. (2012). Therapist and client. A relational approach to psychotherapy. Chichester: Wiley-Blackwell.

North, M. (1972). Personality assessment through movement. London: MacDonald and Evans.

Ogden, P., Minton, K. \& Pain, C. (2006). Trauma and the body, a sensorimotor approach to psychotherapy. London: W.W. Norton.

Ogden, P. \& Fisher, J. (2015). Sensorimotor psychotherapy: Interventions for trauma and attachment. New York: Norton. 
Payne, H. (1990). Creative movement and dance in group work. Oxon: Speechmark publications.

Payne, H. (Ed.) (1992). Dance movement therapy: Theory and practice. London: Routledge Payne H (1994) Dance movement therapy, In: D Jones (ed) Innovative therapy. Milton Keynes: Open University.

Payne, H. (2006a). Tracking the web of interconnectivity. Journal of Body, Movement and Dance in Psychotherapy, 1(1), 7-16.

Payne, H. (2006b) (Ed.) Dance movement therapy: theory, research and practice. London and New York: Routledge.

Payne, H (2006c) The body and container and expresser: Authentic movement groups in the development of wellbeing in our bodymindspirit. In: J Corrigall, H Payne and H Wilkinson, (eds) About a body: Working with the embodied mind in psychotherapy. London and New York: Routledge

Payne, H. (2015). The body speaks its mind: The BodyMind Approach ${ }^{\mathrm{TM}}$ for patients with medically unexplained symptoms in primary care in England. The Arts in Psychotherapy, 42, $19-27$.

Payne, $\mathrm{H}$ and Brooks, S (2016) Clinical outcomes from The BodyMind Approach ${ }^{\mathrm{TM}}$ in the treatment of patients with medically unexplained symptoms in primary health care in England: Practice-based evidence. Arts in Psychotherapy, 47, 1: 55-65

Paxton S (2008) Talk at CI36 (excerpts), Contact Quarterly, 34, 1, Winter/Spring. Retrieved 0512 2015, from: http://www.contactquarterly.com/cq/unbound/view/paxton-talk-at-ci36\#\$

Perls, F., Hefferline, R. F. \& Goodman, P. (1951). Gestalt Therapy. (Re-published 1972) London: Souvenir Press.

Pesso, A. (1969). Movement in psychotherapy, psychomotor techniques and training. New York: U. Press.

Pierrakos, J. (1987). Core Energetics. Developing the Capacity to Love and Heal. Mendocino, CA: LifeRhythm. 
Pylvainen, P. (2003). Body image: A tripartite model for use in dance/movement therapy. American Journal of Dance Therapy, 25, 1, 39-55.

Reich, W. (1949). Character analysis (Theodore P. Wolfe trans.) (3rd enlarged edition). New York: Orgon Institute Press (First German edition published in 1933).

Ren, J. \& Xia, J. (2013). Dance therapy for schizophrenia. Cochrane Database of Systematic Reviews, Issue 10. Art. No.: CD006868. DOI: 10.1002/14651858.CD006868.pub3.

Rogers, C.R. (1961). On becoming a person. Boston: Houghton Mifflin.

Röhricht, F. (2009). Body oriented psychotherapy. The state of the art in empirical research and evidence-based practice: A clinical perspective. International Journal of Body, Movement and Dance in Psychotherapy, 4 (2): 135-156.

Rolef Ben-Shahar, A. (2014). Touching the relational edge: Body psychotherapy. London: Karnac.

Rosenberg, J. Rand, M. L. Asay, D. (1985). Body, Self, and Soul. Atlanta Georgia: Humanics Rothschild, B. (2000). The body remembers: The psychophysiology of trauma and trauma treatment. New York: W. W. Norton.

Rustin, J. (2013). Infant Research and Neuroscience at Work in Psychotherapy, Expanding the Clinical Repertoire. London: W.W. Norton.

Samaritter, R. (2015). Inside the Mirror: effects of attuned dance movement intervention on interpersonal engagement as observed in changes of movement patterns in children and adolescents with autism spectrum disorder. Thesis submitted in partial fulfilment for a PhD, University of Hertfordshire, England.

Samaritter, R. \& Payne, H. (2013). Kinaesthetic intersubjectivity: A dance informed contribution to self-other relatedness and shared experience in non-verbal psychotherapy with an example from autism. The Arts in Psychotherapy, 40, 1: 143-150.

Schaverien, J. (1995). Desire and the female therapist: engendered gazes in psychotherapy and art therapy. London: Routledge. 
Schmais, C. (1974). Dance therapy in perspective. In K. Mason (Ed.), Dance therapy: Focus on dance VII (pp. 7 - 12). Washington: D.C.: American Association for Health, Physical Education and Recreation.

Schmidt, J.G. (2000). Functional relaxation in the treatment of tension headache. ErlangenNuremberg, Friedrich-Alexander-University School of Medicine.

Schore, A. N. (1994). Affect regulation and the regulation of the self: the neurobiology of emotional development. Hillsdale, New Jersey: Lawrence Erlbaum Associates.

Schore, A.N. (2003a). Affect dysregulation and disorders of the self. New York: Norton. Schore, A.N. (2003b). Affect regulation and the repair of the self. New York: Norton. Schore, A. N. (2011). The right brain implicit self lies at the core of psychoanalytic psychotherapy. Psychoanalytic Dialogues, 21, 75-100.

Schore, A.N. (2012). The science of the art of psychotherapy (Norton Series on Interpersonal Biology). W.W. Norton \& Company.

Sella, Y. (2003). Soul without skin, bones with no flesh: bodily aspects of the self in the treatment of women patients with restrictive anorexic eating patterns. International Journal for Psychotherapy, 8, 1: $37-51$.

Serlin, I. A. (2000). Supportive/expressive psychotherapy groups for women with breast cancer: incorporating imagery and movement as arts medicine. The California Psychologist, 33, 3: 26.

Sherborne, V (2001) Developmental movement for children. London: Worth publishing Simon H (1929) Active Treatment in a Residential Centre. Berlin: W. de Gruyter.

Singer, A. J. (2006). Hidden treasures, hidden voices: An ethnographic study into the use of movement and creativity in psychosocial work with war-affected refugee children in Serbia. In H. Payne (ed.) Dance movement therapy: theory, research and practice. (pp 101-111). New York: Routledge.

Skinner B F (1953). Science and human behaviour. New York: McMillan.

Sletvold, J. (2014). The embodied analyst: From Freud to Reich to relationality. London: Routledge. 
Soth, M (1993) Five modalities of the therapeutic relationship.

http://www.integra-cpd.co.uk/cpd-resources/petruska-clarksons-five-modalities-of-thetherapeutic-relationship-1995/ Accessed 10.12.15.

Soth, M. (2009). From humanistic holism via the integrative project towards integralrelational body psychotherapy. In: L. Hartley (Ed.), Contemporary body psychotherapy: The Chiron approach (pp 64-88). London: Routledge.

Staunton, T. (Ed.). Body psychotherapy. Hove: Brunner-Routledge.

Stauffer, K. A. (2010). Anatomy and Physiology for Psychotherapists. Connecting Body and Soul. New York: W. W. Norton.

Stern, D. N. (1985). The interpersonal world of the infant. A view from psycho-analysis and developmental psychology. New York: Basic Books.

Stern, D. (2004). The Present Moment in Psychotherapy and Everyday Life. New York; W. W. Norton.

Stanton-Jones, K. (1992). An introduction to dance movement therapy in psychiatry. London: Routledge.

Tarr, B., Launay, J., Cohen, E. \& Dunbar, R. (2015). Synchrony and exertion during dance independently raise pain threshold and encourage social bonding. Biology Lett. 11: 20150767. DOI:10.1098/rsbl.2015.0767

Thorne F C (1967) Integrative psychology. Brandon: Clinical Publishing. Totton, N. (2003) Body Psychotherapy: An Introduction. Maidenhead, UK: Open University Press.

Totton, N. (2014). Embodiment and the social bond. In: K. White, (Ed.). Talking bodies: How we Integrate working with the body in psychotherapy from an attachment and relational perspective? London: Karnac. (pp. 41-64).

Totton, N. (2015). Embodied Relating: The ground of psychotherapy. International Body Psychotherapy Journal, 13, 2: 88-103.

Trevarthan, C. (2005). Stepping away from the mirror: adventures of companionship. 
Reflections on the nature and emotional needs of infant intersubjectivity. In C.S.

Carter, L. Ahnert, K. E. Grossman, S. B. Hardy, M. E. Lamb, S. W. Porges, \& N. Sachser, (Eds.). Attachment and bonding: a new synthesis (pp. 55-84). Dahlem Workshop Report 92. Cambridge, MA: The MIT Press.

Uvnäs-Moberg, K., Arn I. \& Magnusson, D. (2005). The psychobiology of emotion: the role of the oxytocinergic system. International Journal of Behavioural Medicine, 12, 2:59-65.

Varela, F. J., Thompson, E. \& Rosch, E. (1993). The embodied mind: cognitive science and human experience. Cambridge, MA: The MIT Press.

Warnecke T. (2009). The borderline relationship. In L. Hartley (Ed.), Contemporary body psychotherapy: the Chiron approach (pp. 194-211). London: Routledge.

Warnecke T. (2011). Stirring the depths: Transference, countertransference and touch. International Journal of Body, Movement and Dance in Psychotherapy, 6, 3: 233-244 Warnecke T. (2012). Developing through embodiment and movement. In C. Rose (Ed.) Self awareness and personal development: Resources for psychotherapists and counsellors. Weiss, H., Johanson, G. \& Monda, L. (Eds.) (2015). Hakomi mindfulness-centered somatic psychotherapy: A guide to theory and practice. Berkeley: North Atlantic Books. New York: Palgrave Macmillan.

Westland, G. (2015a). Verbal and non-verbal communication in psychotherapy. New York: Norton.

Westland, G. (2015b). The Field of Body Psychotherapy. In G Marlock and H Weiss with C. Young and M. Soth (Eds) Touch in Body Psychotherapy (pp. 494-508). Berkeley: North Atlantic Books.

White, M., \& Epston, D. (1990). Narrative means to therapeutic ends. New York: W. W. Norton.

Whitehouse, M. (1979). Jung and dance therapy: Two major principles. In P. Bernstein (Ed.), Eight theoretical approaches to dance movement therapy. Dubuque: IA: Kendall / Hunt. 
Young, C. \& Pallaro, P. (2008). A dance across the Atlantic: Correspondence on understanding the difference between definitions and whether dance/movement therapy is a body psychotherapy. International Journal of Body, Movement and Dance in Psychotherapy, 3, 2: 125-133. 